\title{
Ethical Perspectives on Costly Drugs and Health Care
}

\author{
AAN Position Statement
}

\begin{abstract}
Amy Y. Tsou, MD, MSc, William D. Graf, MD, James A. Russell, DO, MS, and Leon G. Epstein, MD, on behalf of the Ethics, Law, and Humanities Committee, a joint committee of the American Academy of Neurology (AAN), American Neurological Association (ANA), and Child Neurology Society (CNS)
\end{abstract}

Neurology ${ }^{\circledR}$ 2021;97:685-692. doi:10.1212/WNL.0000000000012571

\section{Abstract}

High drug prices have created substantial challenges for patients, physicians, health systems, and payers. High drug prices can affect patient care in many ways, including limiting access to treatment, increasing the burden of administrative tasks, and contributing to physician burnout. Exorbitant drug pricing poses direct challenges for distributive justice, which is concerned with fairly distributing benefits and burdens across society. In this position statement, we discuss ethical concerns raised by high drug costs, primarily focusing on concerns around distributive justice. We consider forms of rationing, approaches to allocation, potential complexities in real-life application, and structural forces contributing to high drug costs. Finally, we consider potential policy solutions and ramifications for individual clinicians.

\section{Introduction}

The high cost of drugs has created substantial challenges for patients, physicians, health systems, and payers. Although Americans have long held the dubious distinction of paying more for drugs than patients in other countries, recent price increases have been dramatic. In 2016, Medicare spending on drugs cost $\$ 128.6$ billion, representing $19 \%$ of total Medicare expenditures. ${ }^{1}$ The Centers for Medicare \& Medicaid Services projected that net US spending on prescription drugs will increase faster than any other major health care good or service over the next decade. ${ }^{2}$ These price increases have not been limited to niche or specialty drugs. A 2016 US Government Accountability Office report identified over 300 generic drugs that increased over $100 \%$ in price from 2010 to 2015 in the United States; these included many older drugs such as carbamazepine, amitriptyline, selegiline, and baclofen. ${ }^{3}$

Patients have felt the effects of these changes in many ways, including increased costs. A recent study found that from 2004 to 2016, the mean out-of-pocket costs for commonly prescribed medications for multiple sclerosis increased dramatically from $\$ 15$ to $\$ 309$ per month. ${ }^{4}$ Diabetic patients have seen the cost of insulin rise from $\$ 20-\$ 30$ per vial years ago to around $\$ 300$ per vial today. Expensive drugs with literal life-saving potential such as nusinersen (Spinraza) and onasemnogene abeparvovec (Zolgensma) have illustrated in dramatic fashion the complex tradeoffs inherent in allocating societal resources. ${ }^{5}$

To address this challenge, the American Academy of Neurology (AAN) convened a Task Force on Drug Pricing. ${ }^{6}$ Among the recommendations offered by their work in 2018 was the recommendation that the Ethics, Law, and Humanities Committee (ELHC), a joint committee of the AAN, American Neurologic Association, and Child Neurology Society, offer member guidance on the ethical implications and considerations related to high drug costs. In this article, we discuss ethical concerns raised by these costs, primarily focusing on concerns around distributive justice, many of which have been highlighted by the

\author{
Correspondence \\ Dr. Tsou \\ amytsou@gmail.com
}

\section{MORE ONLINE}

(ค) Podcast

Dr. Gordon Smith talks to

Dr. Amy Tsou about the

paper "Ethical Perspectives on Costly Drugs and

Health Care: AAN Position Statement."

NPub.org/3r66cr 


\section{Glossary}

AAN = American Academy of Neurology; COVID-19 = coronavirus disease 2019; FDA = Food and Drug Administration; QALY = quality-adjusted life-year.

coronavirus disease 2019 (COVID-19) pandemic. We also offer some thoughts about how physicians might begin to address these considerable challenges.

\section{Exorbitant Drug Prices Pose Direct Challenges for Distributive Justice}

Exorbitant drug pricing poses direct challenges for distributive justice, which is concerned with fairly distributing benefits and burdens across society. Within medicine, many ethical issues (e.g., obtaining informed consent, ensuring disclosure of information, resolving disagreements about plan of care) revolve around interactions between doctors and patients. However, the problematic issues raised by high drug prices are distinctive in being primarily generated by forces external to the traditional doctor-patient relationship, specifically industry, payers, pharmacy benefit managers, health systems, and current models of health care financing.

\section{High Drug Costs Limit Treatment Access}

High drug costs pose challenges for distributive justice in many ways, but primarily by potentially limiting access to treatment. This is true for the $8.8 \%$ of Americans who lacked health insurance in 2017. ${ }^{7}$ However, even those with insurance may lack coverage for high-cost interventions. Prior authorization requirements restrict and delay access to care, sometimes with adverse clinical consequences: in a recent survey, $75 \%$ of doctors reported that these requirements can lead to patients abandoning treatment, and $28 \%$ reported that prior authorization requirements had resulted in a serious adverse event. ${ }^{8}$ Even with coverage, many patients still incur significant out-of-pocket expenses that limit their ability to afford treatment, leaving them with grim choices. The effect of dramatic job losses and disruption across wide swaths of the economy due to COVID-19 has further exacerbated existing disparities in access to health care.

To address the challenge of high costs, some patients engage in self-rationing, skimping on medication to save money. In a recent Kaiser Family Foundation survey, 24\% of respondents reported difficulty paying for medication and $29 \%$ reported forgoing medication in the past year due to concerns about cost. ${ }^{9}$ Over half of individuals with employee-sponsored insurance reported postponing recommended treatment for themselves or a family member due to cost. ${ }^{10}$ A recent study demonstrated that even for relatively inexpensive drugs such as gabapentin and pregabalin, increased out-of-pocket costs were associated with lower medication adherence in patients with neuropathy. ${ }^{11}$ Another study found that to save money, 25\% of diabetic patients were using less insulin than prescribed, and $1 / 3$ of these patients did not tell their physician. ${ }^{12}$ Self-rationing can have serious risks for patients: several deaths due to individuals self- rationing insulin have been reported. ${ }^{13}$ However, even when payers choose to provide full coverage, the effect of these expensive drugs is not moot. Given finite resources, an insurance company's choice to cover one expensive therapy may simply result in curtailing coverage for other valuable medical interventions. Alternatively, these costs may simply be passed along to other patients through higher premiums.

\section{Administrative Tasks Detract From Patient Care}

High drug costs also consume another valuable resource: physician time. A mundane but important consequence of exorbitant drug prices is the copious time physicians now spend completing prior-authorization paperwork, phone calls, and other procedures in attempts to procure access. In one survey, physicians reported submitting 31 prior authorization requests per week, expending 14.9 hours or nearly 2 business days per week. ${ }^{8}$ Physicians often act as the de facto information source for patients seeking to know what treatments are possible given their coverage plan; thus, in essence, the onerous task of deciphering coverage rules and communicating them to patients is often now borne by doctors and their staff. These conversations with patients are often complicated, potentially unpleasant, and nearly always time-consuming. ${ }^{14}$ Even prior to the upheaval of the recent pandemic, practicing physicians faced overbearing time constraints and a burden of administrative tasks that directly detracted from patient care. Collectively, these (and other) administrative tasks are so burdensome to physicians and potentially detrimental to care that in 2017, the American College of Physicians called for reassessing the value of all existing and proposed administrative tasks based on their effect on finances, time, and quality of care. ${ }^{15}$

\section{Physician Burnout}

US neurologists have the 2 nd highest rate of burnout across medical specialties, and a recent survey suggested burnout rates may be as high as $60 \% .{ }^{16,17}$ A 2017 qualitative study found that US neurologists specifically cited insurance mandates and prior authorization as factors contributing to dissatisfaction with professional life. ${ }^{18}$ Thus, the burdens of navigating coverage requirements and communicating with patients not only detract from neurologists' ability to care for other patients, but also to care for themselves. If neurologists become inclined to avoid needier patient populations in efforts to diminish these stressors, with time, these vulnerable patients may have less access to neurology specialty care. Many have expressed concerns about a current shortage of neurologists, which some analyses project will worsen in the United States if efforts to recruit more trainees (which the AAN has been actively engaging in) fail. ${ }^{19}$ Burnout may 
compound these problems by incentivizing neurologists to retire earlier.

\section{Rationing of Some Sort Is Inevitable}

Costly treatments inevitably lead to rationing of some sort. Within medicine, the term "rationing" has often carried a powerfully negative valence; however, the tragic necessity of recent widespread rationing of personal protective equipment served as a stark reminder that rationing still occurs in health care. Rationing of ventilators in Italy and planning for such contingencies in the United States has highlighted the agonizing complexity of such decisions that inherently involve judgments that one individual's opportunity to receive lifesustaining therapy deserves priority over another's. ${ }^{20}$

Allocating scarce ventilators during a pandemic is an extreme instance of rationing with immediate life and death consequences. However, other forms of less dramatic rationing are also common and already routine throughout our health system: for example, limitations of access (e.g., insurance coverage or lack thereof, tiered therapy), cost (out-of-pocket expenses), and length of wait times. ${ }^{21}$ As some have pointed out, even the decisions physicians make regarding how much time to spend at each patient's bedside represent a form of implicit rationing. ${ }^{22,23}$ As the world has recently been painfully reminded, rationing is necessary given our finite resources and the fact that resources given to one patient are not necessarily available to others.

\section{Implicit vs Explicit Rationing}

Rationing within health care may be explicit (i.e., based on stated principles or transparent rules), such as the rules governing organ allocation. However, rationing may also be implicit (without formal stated rules or principles), ${ }^{22}$ such as allocation of intensive care unit beds. These decisions occur at both the systems level (macrorationing) and in everyday choices made in providing care to individual patients (microrationing). While either explicit or implicit rationing may prove unfair, some have expressed concern that implicit rationing may be more susceptible to bias, because the absence of clear and transparent criteria may allow inconsistent decision-making. ${ }^{23}$ For instance, introduction of the model for end stage liver disease (MELD) score (which replaced a more subjective system in which transplant physicians advocated for their individual patients based on need) significantly mitigated racial disparities that had existed in allocation among organ recipients. $^{24}$

\section{Approaches to Allocation}

Ethicists have offered several principles that embody different conceptions of how to fairly distribute scarce resources. A utilitarian approach seeks to maximize the overall benefit to society, such as maximizing the number of lives saved or selecting patients with the best prognosis (i.e., to maximize years of life gained). While there are many approaches to quantifying benefit, perhaps the most well-known is the quality-adjusted life-year (QALY). Using this approach, one might calculate the potential QALYs an intervention could provide across different populations and choose to allocate the intervention in a way that generated the most QALYs. Of course, defining and measuring what constitutes "benefit" is complex; also perplexing are conundrums about how to distribute benefits. For instance, how should one choose between providing a large benefit to a single person, or smaller benefits to a much larger group? This approach is also at odds with a deep instinct shared by many that we should help the sickest patients although they may be far less likely to benefit society in the future.

In contrast, a prioritarian approach argues for giving the worst-off patients priority. ${ }^{25}$ Patients receiving priority for allocation could include the sickest patients or the very young who have not had the opportunity to live a normal lifespan. This approach is appealing, in that an individual's worth or usefulness to society does not affect whether he or she should receive priority.

A third approach, egalitarianism, prioritizes providing equal access for all individuals. A lottery system exemplifies this approach to allocation, as all participants have an equal opportunity. Furthermore, lotteries are difficult to game or corrupt, further ensuring equal distribution. However, the emphasis on giving each individual an equal chance can lead to ignoring patient-specific factors many would see as critical for decision-making. These factors include how badly a patient needs the intervention and how likely he or she is to actually benefit. $^{22}$

\section{Complexities of Allocation Decisions in Real Life}

Given the complexities of these decisions, any real-life approach to allocating scarce resources will likely require consideration of multiple principles. For instance, Burgart et al. ${ }^{5}$ thoughtfully consider how these principles might play out in decisions regarding access to nusinersen treatment for spinal muscular atrophy. Nusinersen was originally priced at $\$ 750,000$ for year 1 and $\$ 375,000$ annually thereafter, with additional costs required for administration. Even setting aside the issue of cost, given the pragmatic challenges of intrathecal administration, health systems face the challenge of prioritizing which patients should receive the drug first. For instance, should younger patients with less disability (who may benefit more) receive priority over older patients with more disability? This could lead to a situation where older, sicker patients were continuously set aside in favor of younger patients. Patients living far from the specialized centers necessary to administer the drug also may be penalized. The recent entry of another high-priced biologic drug, onasemnogene abeparvovec (Zolgensma), illustrates the quandary health systems face when choosing to invest. Given the limited supply and extraordinary cost, Novartis has offered Zolgensma for free to patients selected using a lottery, citing it 
as the fairest system. However, some ethicists have raised concerns that accepting the lottery system distracts from the more important question of whether the company should do more to reduce the scarcity. ${ }^{26}$

The extent to which health systems and payers will employ these (or other) approaches to rationing will depend on how scarce a given intervention is. These principles have been used to inform allocation of very scarce resources such as donated organs, but are also applicable to considering how to fairly distribute costly drugs. While both organs and costly drugs can be considered a scarce resource, they differ in fundamental ways. Unlike organs, many of these high-priced drugs are not inherently a scarce resource, but instead, are scarce due to their high price tag. If society decided to allocate more resources to purchasing costly drugs, or if drug prices decreased, there would be no intrinsic reason why more drugs could not be purchased or produced.

Of course, some interventions will legitimately be expensive. The expertise and infrastructure required to develop and manufacture new treatments is resource intensive and requires significant investment of time and financial resources. ${ }^{27}$ Only 1 in 10 drugs entering phase I trials will ultimately win approval. ${ }^{28}$ Developing new and innovative drugs such as onasemnogene abeparvovec or ocrelizumab requires substantial financial investment. However, if high drug prices are the primary driving force behind scarcity, are these high prices justified? Is the way drug companies arrive at prices fair?

\section{Are Drugs Priced Fairly?}

A public surge of interest around how prices are set has been fueled by cases such as the well-publicized actions of "Pharma Bro" Martin Shkreli of Turing Pharmaceuticals, who raised the price of an antiparasitic drug, Daraprim, from $\$ 13.50$ to $\$ 750$ per pill. ${ }^{1}$ As many have pointed out, he was convicted and jailed for unrelated causes: raising the price in this way was perfectly legal. This is because within the US health care system, drug manufacturers set their own prices, which many have argued typically reflect what they feel the market will bear. $^{29,30}$

The exorbitant cost of certain drugs in the United States compared to prices in other countries invites questions regarding how drug companies arrive at prices. In 2013, the arrival of sofosbuvir for hepatitis $C$ kickstarted a conversation about high drug prices: sofosbuvir was priced at $\$ 1,000$ a pill, with a course of treatment costing $\$ 84,000$. However, payers willing to cover this expensive treatment would be unlikely to reap the long-term financial benefits of a healthier patient given how frequently patients switch insurance plans. Even at this price, some analyses concluded sofosbuvir was cost effective. ${ }^{31}$ While US payers wrestled with how to determine coverage given these costs, the list price for 12 weeks of treatment in India was only $\$ 539 .^{32}$
Pharmaceutical companies commonly defend high prices in the United States compared to other countries by arguing that higher prices are necessary to recoup research and development costs. However, a 2017 study of revenues from the top 20 selling drugs found that the difference in price (non-United States vs United States) for these drugs alone would allow companies to recoup all their research \& development costs with $\$ 40$ billion leftover for profit. ${ }^{33}$ Actual profits, of course, are even higher when revenue from other brand name drugs is also counted. Furthermore, even if drug prices were higher in Europe or Canada, the incentives for companies to lower prices in the United States are unclear. ${ }^{34}$ As for-profit entities, these companies are following the dictates of capitalism: as the health economist Uwe Reinhardt wrote, "the sole mandate for the company's board of directors and the managers they hire is to maximize the wealth of the firm's owners without breaking any of the laws."

\section{Not Truly a Free Market}

While companies may argue that high prices are justified as part of a competitive market ecosystem, in fact, the idea of a truly "free market" with regard to drug pricing is clearly false. Drugs are priced higher in the United States compared to other countries because these companies have had important key protections from competition and negotiation; through the patent system, they enjoy a situation more akin to a monopoly. ${ }^{30,35}$ Current laws and regulations are intended to incentivize innovation by shielding manufacturers from competition for an interval of time. With Food and Drug Administration (FDA) approval, new drugs are automatically guaranteed a period of market exclusivity. ${ }^{36}$ Furthermore, patents granted by the US government can last 20 years or more, limiting competition from generic drugs for a substantive period of time. In some cases, after patent expiration, companies may engage in the practice of "product hopping." Current standards allow companies to patent small, nontherapeutic changes to the drug with relative ease: these include tweaks to its coating, salt moiety, or method of administration. Companies are then at liberty to launch an ad campaign encouraging patients to transition (or "hop") to the new form of the drug and discontinue the prior off-patent version. ${ }^{37}$

The power of generic drugs to lower cost through competition is real: drug prices drop to approximately $55 \%$ of the brand name price with 2 generic manufacturers on the market, $33 \%$ with 5 manufacturers, and $13 \%$ with 15 manufacturers. ${ }^{30}$ However, several factors have diminished the ability of generic drugs to affect prices. For one, acquiring approval for generic drugs from the FDA is a lengthy process, often requiring 3-4 years. Also, companies have sometimes engaged in "pay for delay" tactics, in which generic manufacturers are offered large payments to delay or even abandon bringing a generic drug to market. ${ }^{27}$ For instance, a generic manufacturer of the antibiotic Cipro (ciprofloxacin) received \$398 million for agreeing to wait until the drug's patent expired to market its generic version. ${ }^{30}$ A Federal Trade Commission report estimated these agreements cost consumers and taxpayers $\$ 3.5$ billion 
per year. ${ }^{38}$ State laws may also play a role in decreasing use of generic drugs: physicians are still permitted to specify that substitution of generic drugs is not permitted, and in 26 states, pharmacists may not substitute a generic drug for brand name drug without obtaining the patient's consent. ${ }^{30}$

A series of lawsuits including one filed in 2019 by 44 states have alleged that generic drug manufacturers engaged in coordinated price fixing to artificially inflate generic drug prices. $^{39,40}$ If true, this would further confirm that drug prices set by drug manufacturers are unfair and intentionally elevated to maximize profit.

\section{Lack of Negotiating Power}

If prices are high, large health systems can often negotiate lower prices based on their purchasing power. For instance, ocrelizumab was originally deemed too expensive for coverage in the United Kingdom. However, after negotiations with the United Kingdom's National Healthcare System, Roche lowered its price and the drug became available. ${ }^{41}$ The Veterans Affairs health system and other countries pay less for multiple sclerosis drugs, presumably due to negotiating power. ${ }^{42}$ In stark contrast, Medicare is prohibited from negotiating drug prices-a provision included by Congress after aggressive lobbying from the pharmaceutical industry when Medicare Part D was passed. As Medicare accounts for $30 \%$ of all national spending on retail drugs, the inability to negotiate poses a significant handicap for efforts to lower prices through negotiation. ${ }^{1}$

\section{What Policies Might Address These Issues?}

Many policy solutions to address these challenges have been proposed. ${ }^{27}$ A thorough discussion or critical assessment is beyond the scope of this article; however, we provide an overview of some existing efforts with the caveat that the effect of dramatic alterations in the economic landscape caused by COVID-19 may affect trajectory of these policies as well.

To promote availability of generic drugs, the FDA has worked towards speeding the approval process, and, in fact, approved or tentatively approved 1,021 generic drugs in $2018 .{ }^{43}$ From 2008 to 2018, 64\% of drugs approved benefited from programs to expedite approval by the FDA ${ }^{44}$; Nevertheless, 550 off-patent drugs remain without a generic. ${ }^{45}$

Another strategy for obtaining drugs is to import them from other countries. ${ }^{46}$ However, this too is banned under US law in most cases. ${ }^{47}$ Nevertheless, many patients and families have undertaken this risk, even organizing caravans to cross the Canadian border, as the alternative is going without needed medications. ${ }^{48}$

Another intriguing possibility is that the government could manufacture generic drugs itself. ${ }^{49}$ As laid out in recent proposals, such an entrée would only occur in specific situations suggesting "market failure": for instance, if a drug lacked a generic version, or if a drug shortage occurred and only 1 or 2 companies were manufacturing a generic. A group of hospital systems including Intermountain Healthcare and the Mayo Clinic embarked on such a venture in 2018, founding CivicaRx, a not-for-profit company intended to facilitate production of generic drugs to combat drug shortages. ${ }^{50}$

Development of biosimilars, intended to play the role of generics for biologic drugs, may face particular challenges. ${ }^{51}$ Biologic drugs, created by living organisms (instead of chemically synthesized), have more complex structures and require more resources and time to develop. In 2017, one report found that although biologic drugs only represented $2 \%$ of US prescriptions, they accounted for $37 \%$ of net drug spending. ${ }^{52}$ Some have expressed concerns that developing biosimilars has lagged, perhaps because the length and complexity of the development process and difficulty of demonstrating interchangeability essentially create natural monopolies. ${ }^{53}$ Given the disproportionately high contribution of biologic drugs to costs, working to lower costs of these important interventions will be crucial to lowering overall drug costs in the United States.

Another strategy to lower drug prices would be allowing Medicare to negotiate drug prices, a strategy that appears to have broad support across the majority of Americans. In a recent poll, $86 \%$ of Americans supported government negotiation to lower drug prices for Medicare. ${ }^{9}$ However, whether such negotiations could yield significant cost savings would depend on many measures, including, for instance, whether any drug could ever be dropped from coverage on the basis of marginal benefit or exorbitant cost. ${ }^{54}$ Benchmarking Medicare prices against prices other countries pay would be another option. $^{55}$

Other ideas in various stages of development/deployment include value-based pricing (in which the price of the drug is based on the magnitude of its benefit, determined in a transparent manner and based on existing evidence of benefit) and outcome-based contracts (in which payments to manufacturers are conditional on whether the drug achieves its purported outcomes). ${ }^{56,57}$ In 2019, Louisiana embarked on a novel innovative approach to providing hepatitis $\mathrm{C}$ treatment for its Medicaid population. Under this "Netflix" style model, the state agreed to pay a subscription fee to a specific manufacturer in exchange for as much drug as it needs. This allows the state to predict costs and spread them over time, while the manufacturer receives a guaranteed income stream and market exclusivity within the state. ${ }^{58}$

\section{What Does It Mean for Individual Clinicians?}

What does this mean for individual neurologists, as we seek to provide the best care for our patients day by day? For one, 
neurologists should be cognizant of the cost and inherent tradeoffs involved in ordering diagnostic tests, treatment, or medication. If medically necessary, diagnostic and therapeutic interventions should be considered regardless of cost. However, given the many constraints we practice under, it might sometimes be easier to simply acquiesce to the request for "another MRI" or the newest medication for a patient's neurologic disorder, instead of undertaking the hard work of ascertaining whether it is indicated, explaining this rationale to the patient, and (in either scenario) ensuring the underlying concerns prompting the request are addressed. We should remind ourselves that interventions with marginal value cost the system as a whole and take away valuable resources from other patients. Even if structural changes to drug pricing succeed in lowering the cost of many drugs, the societal challenges of caring for populations of patients with limited resources will remain. As such, tiered therapy or treatment algorithms will continue to play a role in balancing the good of individual patients against the needs of the broader populations.

Some neurologists may encounter requests for treatments they do not feel are appropriate. While efforts to respect patient autonomy are necessary and important, physicians should not always feel obligated to yield to patient wishes. In this era of patient satisfaction surveys, physicians should remember that they are ethically justified in setting limits and denying requests for treatments that are not medically indicated or do not provide meaningful medical benefit (e.g., Choosing Wisely ${ }^{59}$ ).

As physicians, our professional code mandates we seek the good of patients. This includes doing our utmost to help our patients gain and maintain access to needed treatment, even if this entails "precertification of everything." Physicians should also incorporate financial considerations into our shared decision-making process with patients when possible. Newer health information technology tools can potentially provide descriptions of out-of-pocket costs to providers at the point of prescribing. Medicare has mandated that all Medicare drug plans integrate electronic Real Time Benefit Tools into their doctors' electronic prescribing system starting in $2021 .^{60}$ Some early evidence suggests such tools could influence prescribing. ${ }^{61}$ While such tools provide valuable opportunities to address cost with patients, given the time constraints most physicians face, using this tool may simply become another task added to the lengthy list physicians must already complete.

Our mandate to seek the good of patients should also impel physicians to advocate for changes to the health care system as a whole. Physicians characteristically consider the care of individual patients to be their primarily professional responsibility. However, as this issue of high drug pricing demonstrates, our ability to care for patients is deeply affected by societal decisions about how to allocate resources. Our current system allows implicit rationing at many levels. These include the opaque process by which drug prices are set, how payers set coverage decisions, and complicated prescription coverage that places an undue burden on patients and clinicians to decipher. The uninsured population in America may also be considered implicit rationing. ${ }^{22}$ Supporting efforts to address these systemic issues is a vital way physicians can contribute to bringing system-level change that enables better care for our individual patients.

Health care and drug manufacturing are complicated and costly enterprises. All nations struggle with their moral obligations to provide health care for their citizens. Questions about the extent to which the private insurance system and the government should be involved are ongoing topics of fraught debate in the United States as we seek to determine whether health care will be valued as a social good or another good for private consumption, subject to pricing and ability to pay. Exacerbation of existing health care disparities by the COVID19 pandemic has highlighted the moral imperative to address these inequities, but also the monumental scale of undertaking such a challenge. Many voices have argued for fundamental changes to health care, such as adopting a singlepayer system, "Medicare for all," or nationalized health care to address inequities that exist within our current system. As expressed by Bernat, "Decisions of where and how to devote health-care dollars turn largely on the values and objectives of our health-care system, as well as on the concept of justice."62 It is tragic and harrowing that patients, particularly in the wealthiest country in the world, should die because they cannot afford insulin—a drug patent licensed for the low price of $\$ 1$ in hopes that this discovery would not be used for profit at the expense of patients. ${ }^{13}$ Moving toward one of these alternative health care systems could allow us to address some of the current issues that challenge fairness.

Alternative financing models for health care could potentially change important aspects of where rationing will occur. However, these tradeoffs will remain ever present. All we can realistically strive for is to choose the least bad system of rationing and ensure that we make explicit choices about rationing that embody what we value.

\section{Acknowledgment}

The authors thank the following individuals for participating in development of this position statement as members of the Ethics, Law, and Humanities Committee: Katharina M. Busl, $\mathrm{MD}, \mathrm{MS}$, University of Florida; Winston Chiong, MD, $\mathrm{PhD}$, University of California at San Francisco; Robin Conwit, MD, National Institutes of Health; Salvador Cruz Flores, MD, Paul L. Foster School of Medicine, Texas Tech University Health Sciences Center; Matthew Kirschen, MD, PhD, Children's Hospital of Philadelphia; Dan Larriviere, MD, JD, Inova Neuroscience and Spine Institute; Julie Kurek, MD, Augusta University; Ariane Lewis, MD, NYU Langone Medical Center; Michael Rubin, MD, MA, UT Southwestern; Ericka P. Simpson, MD, Houston Methodist Hospital; Lynne Taylor, MD, University of Washington; and Benjamin 
Tolchin, MD, MS, Yale University. Sarah Bird Nelson and Karen Kasmirski facilitated discussion and approval of this report as AAN staff.

\section{Study Funding}

The authors report no targeted funding.

\section{Disclosure}

The authors report no disclosures relevant to the manuscript. Go to Neurology.org/ $\mathrm{N}$ for full disclosures.

\section{Publication History}

Received by Neurology April 7, 2021. Accepted in final form July 16, 2021.

\section{References}

1. The Henry J. Kaiser Family Foundation. 10 Essential Facts About Medicare and Prescription Drug Spending. The Henry J. Kaiser Family Foundation; 2019. Accessed June 30, 2019. kff.org/infographic/10-essential-facts-about-medicare-and-prescriptiondrug-spending/

2. Sarpatwari A, Kesselheim AS. Tepid steps on drug pricing. JAMA Intern Med. 2019; 179:439-441.

3. US Government Accountability Office. Generic Drugs Under Medicare: Part D Generic Drug Prices Declined Overall, but Some Had Extraordinary Price Increases; GAO-16-706. US Government Accountability Office; 2016. Accessed June 25, 2019. gao.gov/ products/GAO-16-706

4. Callaghan BC, Reynolds E, Banerjee M, et al. Out-of-pocket costs are on the rise for commonly prescribed neurologic medications. Neurology. 2019;92(22):e2604-e2613.

5. Burgart AM, Magnus D, Tabor HK, et al. Ethical challenges confronted when providing nusinersen treatment for spinal muscular atrophy. JAMA Pediatr. 2018;172(2): 188.

6. American Academy of Neurology. November 2018: AAN task force tackles high neurology drug pricing. Accessed June 30, 2019. aan.com/AAN-Resources/Details/ about-the-aan/board-of-directors/presidents-column/november-2018/.

7. Berchick ER, Hood E, Barnett JC. Health Insurance Coverage in the United States. US Census Bureau; 2017: 44. census.gov/content/dam/Census/library/publications/ 2018/demo/p60-264.pdf.

8. American Medical Association. 1 in 4 doctors say prior authorization has led to a serious adverse event. Accessed June 25, 2019. ama-assn.org/practice-management/ sustainability/1-4-doctors-say-prior-authorization-has-led-serious-adverse.

9. Lopes L, Wu B. KFF Health Tracking Poll: February 2019: Prescription Drugs. The Henry J. Kaiser Family Foundation; 2019. Accessed June 25, 2019. kff.org/healthcosts/poll-finding/kff-health-tracking-poll-february-2019-prescription-drugs/.

10. Hamel L, Muñana C, Brodie M. Kaiser Family Foundation/LA Times Survey of Adults with Employer-Sponsored Health Insurance. Henry J. Kaiser Family Foundation; 2019

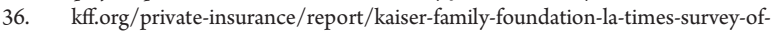
adults-with-employer-sponsored-insurance/.

11. Reynolds EL, Burke JF, Banerjee M, et al. Association of out-of-pocket costs on adherence to common neurologic medications. Neurology. 2020;94(13):e1415-e1426.

12. Herkert D, Vijayakumar P, Luo J, et al. Cost-related insulin underuse among patients with diabetes. JAMA Intern Med. 2019;179(1):112-114.

13. Rosenthal E. When high prices mean needless death. JAMA Intern Med. 2019;179(1) 114-115.

14. Ofri D. Opinion: the Insulin Wars. The New York Times; 2019. Accessed June 25, 2019. nytimes.com/2019/01/18/opinion/cost-insurance-diabetes-insulin.html.

15. Erickson SM, Rockwern B, Koltov M, McLean RM; for the Medical Practice and Quality Committee of the American College of Physicians. Putting patients first by reducing administrative tasks in health care: a position paper of the American College of Physicians. Ann Intern Med. 2017;166(9):659.

16. Medscape. Medscape National Physician Burnout, Depression \& Suicide Report 2019 Accessed June 26, 2019. medscape.com/slideshow/2019-lifestyle-burnout-depression-6011056.

17. Busis NA, Shanafelt TD, Keran CM, et al. Burnout, career satisfaction, and well-being among US neurologists in 2016. Neurology. 2017;88(8):797-808.

18. Miyasaki JM, Rheaume C, Gulya L, et al. Qualitative study of burnout, career satisfaction, and well-being among US neurologists in 2016. Neurology. 2017;89(16) 1730-1738.

19. Burton A. How do we fix the shortage of neurologists? Lancet Neurol. 2018;17(6): 502-503.

20. White DB, Lo B. A framework for rationing ventilators and critical care beds during the COVID-19 pandemic. JAMA. 2020;323(18):1773-1774.

21. Bauchner H. Rationing of health care in the United States: an inevitable consequence of increasing health care costs. JAMA. 2019;321(8):751-752.

22. Scheunemann LP, White DB. The ethics and reality of rationing in medicine. Chest. 2011;140(6):1625-1632.

23. Rosoff PM. Who should ration? AMA J Ethics. 2017;19(2):164-173.
24. Moylan CA, Brady CW, Johnson JL, Smith AD, Tuttle-Newhall JE, Muir AJ. Disparities in liver transplantation before and after introduction of the MELD score. J Am Med Assoc. 2008;300(20):2371-2378

25. Persad G, Wertheimer A, Emanuel EJ. Principles for allocation of scarce medical interventions. Lancet. 2009;373(9661):423-431.

26. Dyer O. Health ministers condemn Novartis lottery for Zolgensma, the world's most expensive drug. BMJ. 2020;368:m580.

27. National Academies of Sciences, Engineering, and Medicine. Making Medicines Affordable: A National Imperative. The National Academies Press; 2018.

28. Biotechnology Innovation Organization, Biomedtracker. Clinical Development Success Rates 2006-2015. Accessed August 16, 2019. bio.org/sites/default/files/Clinical\% 20Development\%20Success\%20Rates\%202006-2015\%20-\%20BIO,\%20Biomedtracker,\%20Amplion\%202016.pdf

29. Time. Why does medicine cost so much? Here's how drug prices are set. Accessed June 28, 2019. time.com/5564547/drug-prices-medicine/.

30. Kesselheim AS, Avorn J, Sarpatwari A. The high cost of prescription drugs in the United States: origins and prospects for reform. JAMA. 2016;316(8):858.

31. Najafzadeh M, Andersson K, Shrank WH, et al. Cost-effectiveness of novel regimens for the treatment of hepatitis C virus. Ann Intern Med. 2015;162(6):407.

32. Iyengar S, Tay-Teo K, Vogler S, et al. Prices, costs, and affordability of new medicines for hepatitis C in 30 countries: an economic analysis. PLoS Med. 2016;13(5) e1002032.

33. Yu NL, Helms Z, Bach PB. R \& D Costs for Pharmaceutical Companies do not Explain Elevated US Drug Prices/Health Affairs. Innovation and Value Initiative. Accessed June 28, 2019. healthaffairs.org/do/10.1377/hblog20170307. 059036/full/.

34. Pauly M. Drug pricing reform in the U.S.: if Europeans paid more, would Americans pay less? LDI. Accessed August 20, 2019. ldi.upenn.edu/healthpolicysense/drugpricing-reform-us-if-europeans-paid-more-would-americans-pay-less

35. Emanuel EJ. Big Pharma's Go-To Defense of Soaring Drug Prices Doesn't Add up. The Atlantic; 2019. Accessed June 28, 2019. theatlantic.com/health/archive/2019/03/ drug-prices-high-cost-research-and-development/585253/

36. Food and Drug Administration. Frequently asked questions on patents and exclusivity. Food and Drug Administration; 2019. Accessed June 30, 2019. fda.gov/drugs/development-approval-process-drugs/frequently-asked-questions-patents-andexclusivity

37. Carrier M, Shadowen S. Pharmaceutical product hopping: a proposed framework for antitrust analysis. Health Affairs. 2017. Accessed June 30, 2019. healthaffairs.org/do/ 10.1377/hblog20170601.060360/full/

38. Federal Trade Commission. Pay for Delay. Federal Trade Commission; 2013. Accessed June 29, 2019. ftc.gov/news-events/media-resources/mergers-competition/paydelay

39. Rosenbaum L. Coalition of attorneys general file third lawsuit against generic drug "price-fixing.". Forbes. Accessed November 23, 2020. forbes.com/sites/leahrosenbaum $/ 2020 / 06 / 10 /$ coalition-of-attorneys-general-file-third-lawsuit-against-generic-drug-price-fixing/

40. Murphy H. Teva and Other Generic Drugmakers Inflated Prices up to 1,000\%, State Prosecutors Say. The New York Times; 2019. Accessed June 29, 2019. nytimes.com/ 2019/05/11/health/teva-price-fixing-lawsuit.html

41. National Institute for Health and Care Excellence. Lower price for MS drug paves the way for positive recommendation from NICE. Accessed June 30, 2019. nice.org.uk/ news/article/lower-price-for-ms-drug-paves-the-way-for-positive-recommendationfrom-nice

42. Hartung DM, Bourdette DN, Ahmed SM, Whitham RH. The cost of multiple sclerosis drugs in the US and the pharmaceutical industry. Neurology. 2015;84(21) 2185-2192.

43. Food and Drug Administration. 2018 Office of Generic Drugs Annual Report. Food and Drug Administration; 2019. Accessed June 30, 2019. fda.gov/drugs/2018-office-generic-drugs-annual-report

44. Darrow JJ, Avorn J, Kesselheim AS. FDA approval and regulation of pharmaceuticals, 1983-2018. JAMA. 2020;323(2):164-176.

45. Stakeholders anxious about FDA losing momentum after Gottlieb exits. Modern Healthcare; 2019. Accessed June 30, 2019. modernhealthcare.com/government/ stakeholders-anxious-about-fda-losing-momentum-after-gottlieb-exits

46. Gupta R, Bollyky TJ, Cohen M, Ross JS, Kesselheim AS. Affordability and availability of off-patent drugs in the United States: the case for importing from abroad: observational study. BMJ. 2018;360:k831.

47. Food and Drug Administration. Is it Legal for Me to Personally Import Drugs? Food and Drug Administration; 2018. Accessed June 30, 2019. fda.gov/about-fda/fda-basics/itlegal-me-personally-import-drugs.

48. Olen H. Opinion: a caravan for insulin demonstrates how the American health-care system is failing us. Washington Post; 2019. Accessed June 30, 2019. washingtonpost.com/ opinions/2019/06/18/caravan-insulin-demonstrates-how-american-health-care-system-is-failing-us/

49. Warren E. Opinion: Elizabeth Warren: It's time to let the government manufacture generic drugs. Washington Post; 2018. Accessed June 30, 2019. washingtonpost.com/opinions/elizabeth-warren-its-time-to-let-the-government-manufacture-generic-drugs/ 2018/12/17/66bc0fb0-023f-11e9-b5df-5d3874f1ac36_story.html

50. Abelson R, Thomas K. Fed up with drug companies, hospitals decide to start their own. The New York Times; 2018. Accessed June 30, 2019. nytimes.com/2018/01/18/ health/drug-prices-hospitals.html

51. Gellad WF, Good CB. Adalimumab and the challenges for biosimilars. JAMA. 2019; 322(22):2171-2172 
52. Roy A. Biologic medicines: the biggest driver of rising drug prices. Forbes. Accessed March 7, 2020. forbes.com/sites/theapothecary/2019/03/08/biologic-medicinesthe-biggest-driver-of-rising-drug-prices/

53. Attebery $\mathrm{P}, \mathrm{Bach} \mathrm{PB}, \mathrm{Ohn} \mathrm{J}$, Trusheim M. Biologics are natural monopolies (part 1): why biosimilars do not create effective competition. Health Affairs. Accessed October 8, 2019. healthaffairs.org/do/10.1377/hblog20190405. 396631 /full/.

54. The Henry J. Kaiser Family Foundation. Searching for savings in Medicare drug price negotiations. The Henry J. Kaiser Family Foundation; 2018. Accessed June 30, 2019. $\mathrm{kff}$. org/medicare/issue-brief/searching-for-savings-in-medicare-drug-pricenegotiations/

55. Pear R. Trump proposes to lower drug prices by basing them on other countries' costs. The New York Times; 2018. Accessed June 30, 2019. nytimes.com/2018/10/25/us/ politics/medicare-prescription-drug-costs-trump.html
56. As a cure for high drug prices, outcomes-based deals aren't delivering yet. Modern Healthcare; 2019. Accessed June 30, 2019. modernhealthcare.com/insurance/curehigh-drug-prices-outcomes-based-deals-arent-delivering-yet

57. Kaltenboeck A, Bach PB. Value-based pricing for drugs: theme and variations. JAMA 2018;319(21):2165-2166

58. Ghee R. Louisiana's journey toward eliminating hepatitis C. Health Affairs. 2019 Accessed June 30, 2019. healthaffairs.org/do/10.1377/hblog20190327.603623/full/.

59. Choosing Wisely. Promoting conversations between patients and clinicians. choosingwisely.org/.

60. Centers for Medicare \& Medicaid Services. Medicare advantage and Part D drug pricing final rule (CMS-4180-F). Accessed July 5, 2019. cms.gov/newsroom/factsheets/medicare-advantage-and-part-d-drug-pricing-final-rule-cms-4180-f

61. Robinson JC, Whaley C, Brown TT, Dhruva SS. Physician and patient adjustment to reference pricing for drugs. JAMA Netw Open. 2020;3(2):e1920544.

62. Bernat J. Ethical Issues in Neurology. Lippincott Williams \& Wilkins, 3rd ed. 2008.

\section{COVID-19 and Neurologic Disease: Call for Papers!}

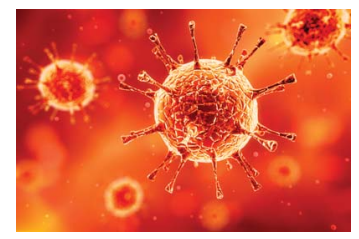

The editors of Neurology are interested in papers that address the neurological aspects of COVID-19 infection and challenges to the management of patients with chronic neurological conditions who have, or are at risk for, the infection. Relevant papers that pass initial internal review will undergo expedited peer review and online publication. We will consider papers posted in preprint servers.

Submit observational studies and clinical trials as Articles and case series and case reports under the Clinical/Scientific Notes category to https://submit.neurology.org/ today!

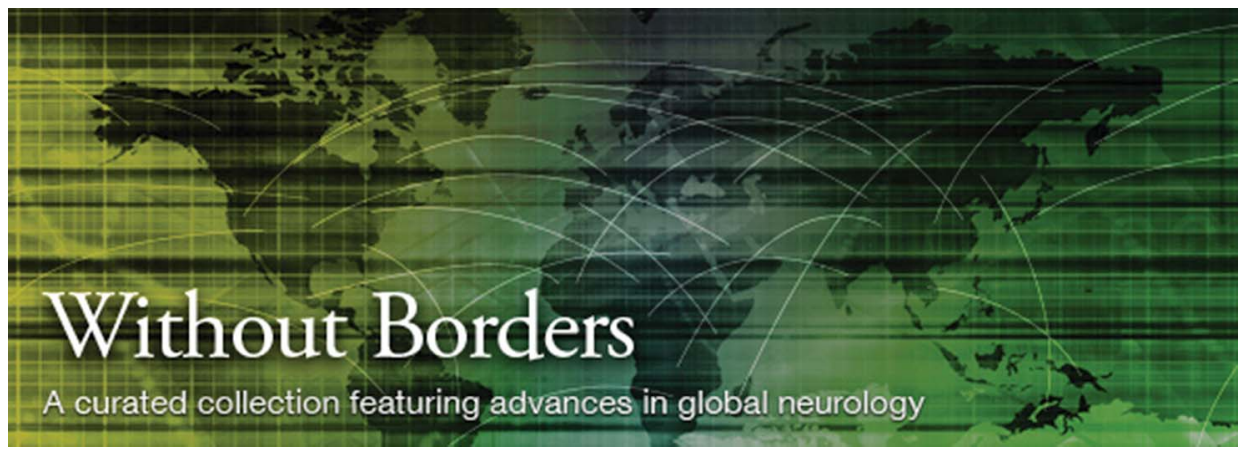

\section{Without Borders - A curated collection featuring advances in global neurology}

This Neurology ${ }^{\circledR}$ special interest website is the go-to source for tracking science and politics of neurology beyond the United States, featuring up-to-the-minute blogs, scholarly perspectives, and academic review of developments and research from Neurology journals and other sources. Curated by Gretchen L. Birbeck, MD, MPH.

Expand your world view at Neurology.org/woborders. 


\section{Neurology}

\section{Ethical Perspectives on Costly Drugs and Health Care: AAN Position Statement}

Amy Y. Tsou, William D. Graf, James A. Russell, et al. Neurology 2021;97;685-692

DOI 10.1212/WNL.0000000000012571

This information is current as of October 4, 2021

$\begin{array}{ll}\begin{array}{l}\text { Updated Information \& } \\ \text { Services }\end{array} & \begin{array}{l}\text { including high resolution figures, can be found at: } \\ \text { http://n.neurology.org/content/97/14/685.full }\end{array} \\ \text { References } & \text { This article cites } 26 \text { articles, } 6 \text { of which you can access for free at: } \\ & \text { http://n.neurology.org/content/97/14/685.full\#ref-list-1 } \\ \text { Subspecialty Collections } & \text { This article, along with others on similar topics, appears in the } \\ & \text { following collection(s): } \\ & \text { Health care reform } \\ \text { http://n.neurology.org/cgi/collection/health_care_reform } & \text { Health disparities } \\ & \text { http://n.neurology.org/cgi/collection/health_disparities } \\ & \text { Structural and social determinants of health } \\ \text { http://n.neurology.org/cgi/collection/structural_social_determinants } & \\ & \text { Information about reproducing this article in parts (figures,tables) or in } \\ & \text { its entirety can be found online at: } \\ \text { http://www.neurology.org/about/about_the_journal\#permissions } & \text { Information about ordering reprints can be found online: } \\ \text { Permissions \& Licensing } & \text { http://n.neurology.org/subscribers/advertise }\end{array}$

Neurology ${ }^{\circledR}$ is the official journal of the American Academy of Neurology. Published continuously since 1951, it is now a weekly with 48 issues per year. Copyright (C 2021 American Academy of Neurology. All rights reserved. Print ISSN: 0028-3878. Online ISSN: 1526-632X.

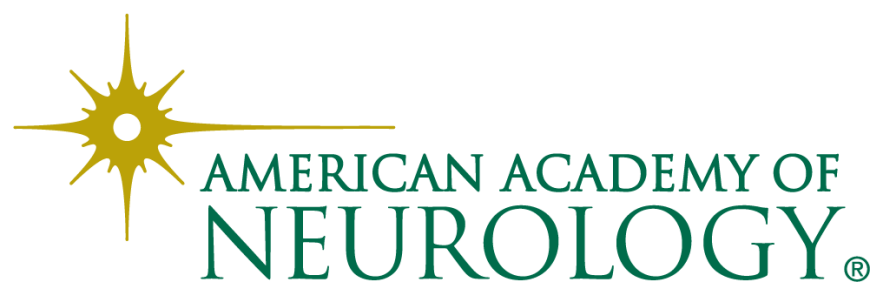

